\title{
An Investigation of the Character Strengths and Resilience of Future Military Leaders
}

\author{
Lobna Chérif, $\mathrm{PhD}^{1}$, Valerie Wood, $\mathrm{PhD}^{2}$, Meaghan Wilkin, $\mathrm{PhD}^{1}$
}

\begin{abstract}
Introduction: The importance of both character and resilience for critical occupations (military, emergency medicine, first responders, and correctional officers) has been emphasized at the highest levels of military leadership. No studies to date have examined the relationship between character strengths and resilience within military populations. The purpose of this study was to evaluate the perceived importance of character strengths for Canadian military cadet success, the top strengths endorsed by cadets, and, in a subset of cadets, the relationships among core strengths and resilience. In line with previous research on character strengths in military populations, we predicted that bravery, honesty, perseverance, and teamwork might be included in the five most frequent signature strengths.
\end{abstract}

Methods: A total of $360 \mathrm{Naval/Officer} \mathrm{Cadets} \mathrm{from} \mathrm{a} \mathrm{Canadian} \mathrm{Military} \mathrm{College} \mathrm{were} \mathrm{invited} \mathrm{to} \mathrm{participate} \mathrm{in} \mathrm{a} \mathrm{study}$ during two training sessions. Participants $(\mathrm{n}=153)$ first completed a survey comprised of a resilience measure and demographic items. Then, one month later, students $(n=134)$ were asked to complete a Values in Action (VIA) character strengths profile, and a survey with questions related to character strengths (their personal top-five character strengths, and strengths they believed were important for military-related stressors and leadership, academic success, resilience, and completion of military challenge). We were only able to match responses for a subset of participants, allowing a final sample of 94 participants.

Results: Findings indicated that military cadets consider perseverance, judgment, teamwork, perspective, and self-regulation to be most critical for bouncing back from stressors. However, in line with our predictions, the most frequently endorsed strengths that characterized cadets were bravery, honesty, and perseverance. Finally, perseverance $(\mathrm{p}=.029)$, bravery $(\mathrm{p}=.01)$, and humor $=.01)$ were positively correlated with cadet resilience, while endorsement of love was negatively correlated with resilience $(\mathrm{p}=.002)$.

Conclusion: Focus on character strengths in military cadets can enhance academic and physical performance. Resilience assessment could be important for the purposes of military selection, performance, and well-being. Our findings indicate perseverance, bravery, and humor in particular might be relevant indicators of cadet resilience.
DOI: $10.18297 /$ jwellness/vol3/iss $1 / 2$

Received Date: Sept 21, 2020 Accepted Date: Nov 16, 2020 Publication Date: Jan 11, 2021 Website: https://ir.library.louisville.edu/ jwellness/

Recommended Citation: Cherif, Lobna; Wood, Valerie; and Wilkin, Meaghan (2021) "An Investigation of the Character Strengths and Resilience of Future Military Leaders" Journal of Wellness: Vol. 3 : Iss. 1 , Article 2.

Affiliations: 'Royal Military College of Canada, ${ }^{2}$ Queen's University - Kingston, Ontario

\section{(i)}

\section{INTRODUCTION}

Leadership is a potent combination of strategy and character. But if you must be without one, be without strategy.

- General H. Norman Schwarzkopf Jr [1].

The importance of a soldier's character, relative to their brawn, has been emphasized since the dawn of North American military. While many have emphasized the importance and relevance of a soldier's character, a widely accepted definition of character has not been clearly established. The US Army has defined character as "an individual's moral and ethical qualities... who a person is, what a person believes, how a person acts..." [2]. Within the academic literature, character can be thought of as, "those impenetrable and habitual qualities within individuals, and applicable to organizations that both constrain and lead them to desire and pursue personal and societal good" [3]. Character has a driving influence on many aspects of one's life, influencing the decisions that a person makes, their behavior, and their reputation. Therefore, in order to better understand a military member's behaviour and decisions, it is important to consider important and defining details of character, particularly the strengths that characterize them.

${ }^{*}$ Correspondence To: Valerie Wood

Email: valerie.wood@queensu.ca
In 2004, Peterson and Seligman sought to identify ubiquitous character strengths, or positive traits that individuals possess, that enable growth, flourishing and moral excellence [4]. Characteristics must meet a number of criteria: contribute to a fulfilling life, morally valued, have undesirable opposites, trait-like, and have institutions or rituals dedicated to their celebration. In addition the virtues and character strengths must explain not only an individual's values, beliefs and thoughts, but also their motivations and behaviours. As a result, 24 character strengths were identified, grouped into six larger virtues, and deemed ubiquitous or cross-culturally recognized and valued. These strengths are assumed to be continuous, with each individual possessing these strengths to varying degrees. However, each of us has a more limited set of core 'signature strengths' which are thought to most strongly motivate and guide our behaviour.

Research on Peterson and Seligman's character strengths classification system has flourished over the past 15 years [5]. While several military doctrines emphasize the importance of character for successful military leadership (e.g., United States, New Zealand, Australia, Argentina, and Canada), there is limited empirical research evaluating character strengths

Copyright: @ 2021 The author(s). This is an open access article distributed under the terms of the Creative Commons Attribution 4.0 International License (CC BY 4.0), which permits unrestricted
use, distribution, and reproduction in any medium, provided the original author and source are credited. 
in military populations. Such knowledge could help inform selection procedures, identifying candidates that are most likely to be competent and resilient leaders. Potential additional benefits include informing military training programs how to build character strengths known to predict success in military occupations. Matthews and colleagues investigated differences in character strengths self-reported by U.S. and Norwegian military cadets relative to a group of similarly-aged U.S. civilians [6]. They found that the profiles of the two military samples were more similar compared to the civilian sample, and the strongest character strengths among the two military samples were honesty, hope, bravery, and teamwork. Another study of 95 male applicants to the Australian Army Special Forces found that the applicants most strongly reported the four strengths of integrity, teamwork, persistence, and love of learning. In a second study, applicants with teamwork as a core strength were 2.6 times more likely to pass the selection process [7]. Finally, Boe and Bang found that leadership, persistence, bravery, teamwork, fairness, social intelligence, love of learning, perspective, self-regulation, and creativity were identified as particularly relevant and important for succeeding as an officer in the Norwegian Army [8].

Overall, these studies suggest that the character strengths of bravery, honesty/integrity, persistence, and teamwork, in particular, are consistently reported by military cadets, the future military leaders, on an international level.

The importance of resilience for critical occupations such as the military (but also including those in emergency medicine, first responders, and correctional officers) cannot be overstated. In such occupations, workers perform critical duties to protect and serve the public. The nature of these jobs exposes workers to events and conditions that critically impact their mental and physical well-being (e.g., long work hours, nonstandard schedules, dangerous tasks, and a physically demanding work environment). The importance of resilience in the military in particular is highlighted at the highest levels of military and defense leadership in countries such as Canada [9]. Highly resilient individuals are those with the capacity to bounce back in the face of adversity or challenge [10]. It is generally understood that resilience, like the character strengths, can be built and developed $[11,12]$. The character strength persistence resembles resilience, as both reflect one's ability to cope and adapt in the face of adversity. Therefore, it is perhaps not surprising that researchers have investigated the relationship between character strengths and resilience. Although it is clear from the literature that there are relationships among resilience and character strengths, the nature of these relationships is not consistent across studies $[13,14,15,16]$. This is likely a reflection of differences in how resilience has been assessed (recovery from psychological and physical illness, self-report scales, and presence of psychological disorders), and how character strengths were analyzed (independently, and grouped by factor analysis).

While the importance of character strengths and resilience in military populations, particularly military leaders, has been touted by military organizations and academics alike, no studies to date have examined the relationship between character strengths and resilience within a military population. Knowing which character strengths are most related to resilience in military members would be beneficial to military organizations, potentially having implications for selection and training. However, the importance of understanding resilience in critical occupations through the lens of stable character traits has been highlighted [17].

For this reason, we investigated the relationships among character strengths and resilience in a group of Canadian military cadets. Specifically, we were interested in assessing the following: 1) military cadets' perceptions of the most important character strengths for academic, leadership, resilience, and successful completion of a rigorous military challenge; 2) the 5 most frequent signature strengths reported by military cadets; and 3) relationships among military cadets' signature strengths and resilience. We could not make informed predictions for research goals one and three, given the paucity of research on perceptions of the importance of character strengths in particular domains by military cadets and relationships among character strengths and resilience in military populations. In addition, there are a number of inconsistencies in how the relationships among character strengths and resilience have been investigated. In terms of the second research goal, we predicted that bravery, honesty, perseverance, and teamwork might be included in the five most frequent signature strengths, given the literature on character strengths in military populations.

\section{METHODS}

\section{Participants and Procedure}

A total of $360 \mathrm{Naval} /$ Officer Cadets (N/OCdts) from a Canadian Military College were invited to participate in a study that took part during two of their training sessions. While the students were obligated to attend the sessions as part of their military training, they were informed that they were free to decline answering any questions on the surveys and face no penalties or repercussions (military nor academic) for not participating in any aspects of the study.

In the first session, participants were asked to complete the online survey containing our resilience measure and demographic items. A total of 153 students completed the survey (response rate of $42.5 \%$ ). In the second session (one month later), students were asked to 1) complete the VIA (Values in Action) Adult Survey ${ }^{1}$ to identify their character strengths profile (from the website viacharacter.org), and then 2) complete our second survey which contained 5 questions related to character strengths. A total of 134 students completed this survey (response rate of $37.2 \%$ ). Specifically, we asked participants to identify the top 7 character strengths they believe were most important for 1) military officers to successfully manage military-related stressors and demands and be an effective military leader, 2) Officers Cadets students, in terms of being able to successfully manage academic-related stressors and demands, and achieve academic success, 3) Officer Cadets students' resilience, specifically in terms of being able to successfully manage demands or stressors and bounce back from adversity, and 4) Officer Cadets students' ability to successfully complete the 'Ex Blizzard Nordique"2 (a mentally and physically challenging military operation). Finally, participants were asked to report their top 5 character strengths from the VIA survey. We could only match responses for 94 participants (the number that completed both components of the study, or that provided two matching participant-generated identity codes). Therefore, we had a final sample of 94 participants between 18 to 32 years of age $(\mathrm{M}=18.99, \mathrm{SD}$ $=.24$ years). Participants were mostly male (60.6\%), English speaking $(72.3 \%)$, and in their first year of study (73\%). Ethical clearance was obtained by the institutional research review board prior to data collection.

\footnotetext{
1. The VIA Adult Survey It is a psychometrically validated personality test that measures an individual's character strengths, that is offered by the VIA Institute, a non-profit organization dedicated to the creation and validation of character strengths surveys, and run by Dr. Martin Seligman (among others).

2. Each year, participants of Ex Blizzard Nordique are presented with a different challenge centered around familiarizing themselves with the basics of winter survival (e.g., facing lake waters in $-10^{\circ} \mathrm{C}$ weather).
} 
Table 1: Frequency of Character Strengths perceived to be important by N/OCdts for each domain

\begin{tabular}{|c|c|c|c|}
\hline Domain & $\begin{array}{l}\text { Ranked Character } \\
\text { Strengths }\end{array}$ & \# Students & $\%$ Students \\
\hline \multirow[t]{5}{*}{ Academics } & Perseverance & 87 & $65 \%$ \\
\hline & Teamwork & 83 & $62 \%$ \\
\hline & Leadership & 77 & $57 \%$ \\
\hline & Self-Regulation & 70 & $52 \%$ \\
\hline & Love of Learning & 67 & $50 \%$ \\
\hline \multirow[t]{5}{*}{ Blizzard } & Perseverance & 85 & $77 \%$ \\
\hline & Judgement & 67 & $61 \%$ \\
\hline & Teamwork & 51 & $46 \%$ \\
\hline & Perspective & 45 & $41 \%$ \\
\hline & Self-Regulation & 44 & $40 \%$ \\
\hline \multirow[t]{5}{*}{ Leadership } & Leadership & 165 & $89 \%$ \\
\hline & Teamwork & 123 & $66 \%$ \\
\hline & Bravery & 115 & $62 \%$ \\
\hline & Perseverance & 110 & $59 \%$ \\
\hline & Judgement & 96 & $52 \%$ \\
\hline \multirow[t]{5}{*}{ Stress Rebound } & Perseverance & 85 & $77 \%$ \\
\hline & Judgement & 67 & $61 \%$ \\
\hline & Teamwork & 51 & $46 \%$ \\
\hline & Perspective & 45 & $41 \%$ \\
\hline & Self-Regulation & 44 & $40 \%$ \\
\hline
\end{tabular}

Note. Based on a sample of $\mathrm{n}=134$ Cadets (Academics); $\mathrm{n}=110$ Cadets (Blizzard); $\mathrm{n}=186$ Cadets (Leadership); $\mathrm{n}=110$ Cadets (Stress Rebound).

\section{Resilience}

We assessed resilience using the Brief Resilience Scale (BRS) [18]. The BRS contains 6 items (e.g., "I tend to bounce back quickly after hard times" and "It does not take me long to recover from a stressful event") and responses are indicated on a scale from 1 (strongly disagree) to 5 (strongly agree). After reverse scoring relevant items, higher scores indicate higher levels of resilience. Scale scores for this sample indicated good reliability (Cronbach's $\alpha=.76)$ [19].

\section{Data Analytic Approach}

We had three research goals. The first research goal was to assess military cadets' perceptions of the most important character strengths for academic, leadership, resilience, and successful completion of the Ex Blizzard Nordique. To do so, we calculated the number of students who mentioned each character strength within each category, regardless of place in the list. In other words, we collapsed across the five strengths mentioned for each category and reported the frequencies of strengths mentioned.

The second research goal was to assess the five most frequent signature strengths that actually characterized this group of military cadets. Again, we used a frequency analysis to determine overall, the frequency of strengths mentioned as being one of cadets' personal top five or signature strengths.

The third research goal was to examine relationships among OCdts/NCdts personal signature strengths and their resilience scores. In order to do this, we conducted two analyses. First, we conducted Spearman's $\rho$ correlations to assess whether resilience scores were related to the rank order of each character strength. In other words, this analysis indicated whether, among cadets' top five strengths, higher ranked strengths were more or less related to resilience scores. This previous analysis only focused on placement of particular character strengths within one's list signature strengths, however we were also interested in assessing whether simple inclusion of each character strength within one's list of signature strengths was associated with resilience scores. In other words, the previous analysis only assessed the importance of particular character
Table 2: Frequency of Signature Strengths endorsed by N/OCdts

\begin{tabular}{lrr}
\hline Character Strengths & \# Students & \% Students \\
\hline Honesty & 48 & $52 \%$ \\
Humor & 36 & $39 \%$ \\
Bravery & 30 & $32 \%$ \\
Fairness & 24 & $26 \%$ \\
Perseverance & 23 & $25 \%$ \\
Curiosity & 23 & $25 \%$ \\
\hline
\end{tabular}

Note. Based on a sample of $\mathrm{n}=93$ Cadets

strengths within the list of top five strengths, but did not differentiate differences among strengths listed or not listed in one's top five in relation to resilience. To do this, we then conducted logistic regression analyses with resilience as the predictor and the presence (coded as 1) or absence (coded as 0 ) of each character strength in one's top five signature strengths list as the outcomes.

\section{RESULTS}

We report findings of the five most frequent Character Strengths for each category in Table 1. Perseverance was identified as the most important character strength for three of the four domains (all but leadership) and cadets reported the same strengths to be important for both successfully rebounding from stress and successful completion of the Ex Blizzard Nordique challenge. Next, the frequency of strengths most commonly reported by N/OCdts were, in order, honesty, humor, bravery, perseverance, and curiosity (see Table 2). The results from our third analysis, an assessment of the relationship between resilience and the rank order of each character strength, are provided in Table 3. Specifically, higher ranks of the character strength perseverance within one's list of signature strengths were associated with higher resilience scores $(\rho=.46, p .029)$. Finally, we used logistic regressions to assess whether simple inclusion of each character strength within one's list of signature strengths was associated with resilience scores.

Table 3: Spearman's $p$ correlations among N/OCdts' Signature Strengths and mean resilience scores

\begin{tabular}{lcccc}
\hline Character Strength & $\mathrm{M}$ & $\mathrm{SD}$ & $\rho$ & $p$ \\
\hline Appreciation of Beauty/Excellence & 2.94 & 1.64 & .10 & .704 \\
Bravery & 2.50 & 1.43 & .12 & .523 \\
Creativity & 2.81 & 1.63 & -.15 & .510 \\
Curiosity & 2.96 & 1.30 & -.04 & .854 \\
Fairness & 3.21 & 1.14 & -.17 & .429 \\
Forgiveness & 3.21 & 1.19 & .35 & .224 \\
Gratitude & 3.08 & 1.00 & -.01 & .976 \\
Hope & 2.63 & 1.38 & .04 & .860 \\
Honesty & 2.64 & 1.51 & -.21 & .153 \\
Humility & 3.67 & 1.11 & .35 & .205 \\
Humor & 3.51 & 3.67 & .01 & .937 \\
Judgement & 3.18 & 1.56 & -.18 & .430 \\
Kindness & 3.35 & 1.46 & .11 & .673 \\
Leadership & 2.91 & 1.58 & -.11 & .754 \\
Love & 2.69 & 1.40 & .04 & .887 \\
Love of Learning & 3.33 & 1.09 & .06 & .816 \\
Perseverance & 2.91 & 1.20 & $.46^{*}$ & .029 \\
Perspective & 3.21 & 1.42 & -.25 & .389 \\
Prudence & 2.80 & 1.32 & -.10 & .677 \\
Self-Regulation & 3.15 & 1.68 & .31 & .309 \\
Social Intelligence & 3.46 & 1.20 & .52 & .069 \\
Spirituality & 3.00 & 1.61 & -.15 & .658 \\
Teamwork & 2.89 & 1.27 & -.10 & .807 \\
Zest & 3.50 & 1.51 & .20 & .460 \\
\hline
\end{tabular}

Note. $M$ and $S D$ stand for mean and standard deviation, respectively. "denotes $p<.05$. 


\begin{tabular}{lccccccc}
\hline Character Strength & $B$ & $S E$ & Wald $\chi^{2}$ & $p$ & OR & \multicolumn{2}{c}{$95 \%$ Cl of OR } \\
\cline { 6 - 8 } & & & & & & Lower & Upper \\
\hline Appreciation of Beauty/Excellence & 0.06 & 0.40 & 0.02 & .881 & 0.94 & 0.43 & 2.07 \\
Bravery & $\mathbf{1 . 0 0}$ & $\mathbf{0 . 3 9}$ & $\mathbf{6 . 7 1}$ & .010 & $\mathbf{2 . 7 3}$ & $\mathbf{1 . 2 8}$ & $\mathbf{5 . 8 9}$ \\
Creativity & 0.47 & 0.39 & 1.45 & .229 & 0.05 & 0.74 & 3.45 \\
Curiosity & 0.54 & 0.36 & 2.25 & .133 & 0.58 & 0.29 & 1.18 \\
Fairness & 0.01 & 0.36 & 0.001 & .980 & 1.01 & 0.50 & 2.03 \\
Forgiveness & 0.13 & 0.43 & 0.09 & .764 & 0.88 & 0.38 & 2.05 \\
Gratitude & -0.30 & 0.46 & 0.42 & .516 & 0.74 & 0.30 & 1.83 \\
Hope & -0.37 & 0.39 & 0.92 & .337 & 0.69 & 0.33 & 1.47 \\
Honesty & 0.11 & 0.31 & 0.12 & .725 & 0.68 & 0.61 & 2.05 \\
Humility & 0.02 & 0.42 & 0.01 & .972 & 0.99 & 0.43 & 2.26 \\
Humor & $\mathbf{0 . 9 0}$ & $\mathbf{0 . 3 6}$ & $\mathbf{6 . 2 2}{ }^{*}$ & .013 & $\mathbf{2 . 4 5}$ & $\mathbf{1 . 2 1}$ & $\mathbf{4 . 9 6}$ \\
Judgement & 0.05 & 0.37 & 0.02 & .900 & 0.96 & 0.47 & 1.96 \\
Kindness & 0.46 & 0.40 & 1.32 & .250 & 0.63 & 0.29 & 1.39 \\
Leadership & 0.40 & 0.50 & 0.64 & .423 & 1.50 & 0.56 & 4.02 \\
Love & $\mathbf{- 1 . 4 5}$ & $\mathbf{0 . 4 7}$ & $\mathbf{9 . 3 3 ^ { * * }}$ & .002 & $\mathbf{0 . 2 4}$ & $\mathbf{0 . 0 9}$ & $\mathbf{0 . 6 0}$ \\
Love of Learning & 0.30 & 0.41 & 0.56 & .454 & 1.36 & 0.61 & 3.00 \\
Perseverance & 0.47 & 0.38 & 1.54 & .214 & 1.60 & 0.76 & 3.37 \\
Perspective & 0.44 & 0.43 & 0.02 & .307 & 0.64 & 0.28 & 1.50 \\
Prudence & 0.68 & 0.39 & 3.05 & .081 & 0.51 & 0.24 & 1.09 \\
Self-Regulation & 0.02 & 0.45 & 0.01 & .967 & 0.98 & 0.41 & 2.37 \\
Social Intelligence & 0.39 & 0.47 & 0.71 & .401 & 1.48 & 0.59 & 3.71 \\
Spirituality & 0.36 & 0.50 & 0.52 & .471 & 1.44 & 0.54 & 3.83 \\
Teamwork & 0.37 & 0.55 & 0.46 & .499 & 1.45 & 0.50 & 4.24 \\
Zest & 0.10 & 0.42 & 0.05 & .818 & 1.10 & 0.49 & 2.49 \\
\hline
\end{tabular}

Note. $B=$ unstandardized regression coefficient; $S E=$ standard error of $B ; \mathrm{OR}=$ odds ratio of $B ; \mathrm{Cl}=$ confidence intervals

${ }^{*} p<.05$

${ }^{* *} p<.01$

Table 4 shows the regression coefficients, Wald statistics, odds ratios, and $95 \%$ confidence intervals for odds ratios for each of the character strengths (as signature strengths) as predictors on resilience. According to the Wald criterion, higher levels of resilience were associated with inclusion of bravery in one's list of top five signature strengths $[\mathrm{c} 2(1, \mathrm{~N}=94)=6.71, \mathrm{p}=$ $.010]$, in addition to humor [ $22(1, \mathrm{~N}=94)=6.22, \mathrm{p}=.010]$. However, inclusion of love in one's list of signature strengths was associated with lower levels of resilience [c2 $(1, \mathrm{~N}=94)$ $=-1.45, \mathrm{p}=.002]$.

\section{DISCUSSION}

The goal of this research was to examine the resilience of a group of Canadian Naval and Officer Cadets, from the perspective of character strengths4. In particular, we were interested in assessing 1) military cadets' perceptions of the most important character strengths for academic, leadership, resilience, and successful completion of a rigorous military challenge; 2) the 5 most frequent signature strengths' reported by military cadets; and 3) relationships among military cadets' signature strengths and resilience. In terms of our first research goal, we did not make clear predictions given the paucity of research on perceptions of the importance of character strengths in particular domains by military cadets. However, we found that perseverance was identified as the most important character strength for three of the four domains, all but leadership (of which leadership was the top listed strength). In addition, perseverance and teamwork were listed as important for all domains, occurring in the top five most frequently mentioned strengths in each category. Finally, it is interesting to note that cadets reported the same strengths, in the same order, as important for both successfully rebounding from stress and successful completion of the Ex Blizzard Nordique challenge. Specifically, cadets thought that perseverance, judgment, teamwork, perspective, and self-regulation were important for successful completion of a physical and psychologically challenging military task, and for one's ability to bounce back from stressors (i.e., resilience). In other words, being able to push through and accomplish a task in the face of threat and obstacles, using sound judgement, being an effective team member, and having perspective and strong self-regulation, were all deemed top qualities of a cadets' character.

In terms of the second research goal, assessing the five most frequent signature strengths that characterized these military cadets, we predicted that bravery, honesty, perseverance, and teamwork might be among those included in the five most frequent signature strengths, given the literature on character strengths in military populations [6,7]. In line with this research, bravery, honesty, and perseverance were some of the most commonly reported signature strengths by N/OCdts. Additional common strengths included humor and curiosity (of the virtues wisdom and transcendence, respectively). Therefore, the actual strengths that characterized this group of military Cadets were bravery, honesty, perseverance, humor, and curiosity.

Finally, for our third research goal, we were interested in assessing relationships among the signature strengths reported by Military Cadets and resilience. Again, we could not make informed predictions given the limited research published on the relationships among reported character strengths of military cadets and resilience. With this in mind, we found that cadets who listed bravery and humor as a signature (top 5) strength were more resilient than those who did not list these signature strengths. This is line with research by Peterson and 
colleagues who found that adults who both experienced and recovered from a physical illness reported greater bravery and humor (among others) [13]. However, and interestingly, those that listed love in their top 5 strengths were less resilient than those without love in their top five strengths. The strength of love involves both loving others and the willingness to accept love from others. Much research demonstrates the supportive nature of close relationships for individual and team resilience. Indeed, close supportive relationships are seen as antecedent to resilience $[20,21,22]$. Therefore, this finding was quite surprising. While this is speculative, it is possible that for this group of Military Cadets, being more dependent on others (e.g., for emotional support) is either perceived as, or truly experienced as, an impediment to resilience, in that resilience is seen as a personal virtue involving successful and independent regulation of emotion and overcoming of obstacles. This is in line with research demonstrating a relationship between empathy, compassion fatigue, and burnout among those in high stress professions like social workers, police officers, and physicians $[23,24,25]$. It is also possible that this finding is a reflection of other traits being more closely linked to resilience; for those who didn't list love as a signature strength, the traits that they did list were more related to resilience (like bravery).

Finally, another way to assess the relationship between strengths and resilience is to examine, among the list of signature strengths provided by cadets, the relationship between rank of the signature strength and resilience. When we examined this, we found that the higher perseverance was ranked as a signature strength, the more resilient cadets were. This makes sense, given how conceptually close perseverance seems to be to resilience. In fact, perseverance is deemed a component of resilience in some resilience scales [26].

Knowledge of which character strengths are best associated with resilience could have important implications for personnel selection and training in military occupations and critical occupations more broadly. For example, if future research continues to support the notion that particular character strengths are related to greater resilience or recovery from training exercises, such strengths could be used as selection criteria. Indeed, initial findings from our study and those of Gayton and Kehoe do suggest that the strengths of teamwork, honesty, persistence, humor and bravery in particular might be important predictors of later resilience [7]. In addition, Matthews showed that American military cadets who completed basic training $(\mathrm{n}=1135)$ were higher in the strengths of teamwork, honesty, persistence, and bravery (among others) than the small number of cadets $(n=73)$ who did not complete basic training [6]. Building upon the positive psychology paradigm by selecting military leaders and assessing military personnel upon specific character strengths could be a healthy approach to selection. In addition to selection, there is ample evidence that character strengths can be developed through strengths-based positive psychology interventions [12]. In other words, regardless of the character strengths reported by military cadets and entrants, military training programs (and potentially other critical occupation training programs) might benefit from building those strengths most strongly correlated with resilience, and assess their efficacy. Integrating the development of character in training and education programs, and continuing to build those same character strengths initially selected for, might be valuable in fostering the resilience of our future military leaders.

\section{LIMITATIONS}

One of the main limitations of this research is that we didn't collect (nor have access to) the raw scores for each of the character strengths, or the extent to which each of the strengths is reported by cadets. Having continuous scores for each of the strengths would have allowed us to better assess the relationships among resilience and the strength of reported character strengths. Therefore, future researchers should request access to this information to better assess relationships among character strengths and other variables. In addition, the use of self-reports is accompanied by concerns with mono-method variance and social desirability.

The resilience measure includes a similar number of negative and positive items to reduce the effects of social desirability and positive response biases, and the VIA Institute found that Marlowe-Crowne social desirability scores did not significantly correlate with character strengths scale scores, with the exception of prudence $(r=.44)$ and spirituality $(r=.30)$. In addition, even if social desirability lead to potentially inflated overall scores of character strengths or resilience, we do not expect that social desirability can explain reported relationships among resilience and the presence of particular signature strengths. Due to the cross-sectional nature of this design, conclusions about causality cannot be made. Therefore, we are not able to determine whether more resilient individuals learn to value and develop particular character strengths, or whether particular strengths of character predispose one to be resilient. Future research could use strengths-based interventions, for example, to better elucidate causality between strengths and resilience [12].

\section{CONCLUSION}

Focusing on the character strengths best associated with military cadet academic and physical performance, and resilience could have important implications for personnel selection and training in military occupations and critical occupations more broadly. Our findings indicate that perseverance, bravery, and humor in particular might be relevant indicators of cadet resilience. In particular, the more that cadets value perseverance, the more resilient they are likely to be. However, our findings indicate that cadets that highly value love might experience challenges in bouncing back in the face of adversity.

\section{REFERENCES}

1. Kruse K. Norman Schwarzkopf: 10 Quotes on leadership and war. Retrieved, Sep. 2012 Dec 27;8:2015.

2. Michelson BM. Character Development of US Army Leaders: A Laissez Faire Approach. ARMY WAR COLLEGE CARLISLE BARRACKS PA; 2013 Mar.

3. Wright TA, Lauer TL. What is character and why it really does matter. https://doi.org/10.1016/j. orgdyn.2012.12.004..

4. Peterson C, Seligman ME. Character strengths and virtues: A handbook and classification. New York: Oxford University Press and Washington. DC: American Psychological Association; 2004.

5. Niemiec RM. VIA character strengths: Research and practice (The first 10 years). In Well-being and cultures. Dordrecht: Springer; 2013. pp. 11-29.

6. Matthews MD, Eid J, Kelly D, Bailey JK, Peterson C. Character Strengths and Virtues of Developing Military Leaders: An International Comparison. Mil Psychol. 2006;18 sup1:S57-68.

7. Gayton SD, Kehoe EJ. A prospective study of character strengths as predictors of selection into the Australian army special force. Mil Med. 2015 Feb;180(2):151-7.

8. Boe O, Bang H. The big 12: the most important character strengths for military officers. Athens Journal of Social Sciences. 2017;4(2):161-74.

9. Canada. Department of National Defence. Guidance to the Canadian Armed Forces. Ottawa: DND Canada; 2013.
JOURNAL 
10. Coutu DL. How resilience works. Harv Bus Rev. 2002 May;80(5):46-50.

11. Joyce S, Shand F, Tighe J, Laurent SJ, Bryant RA, Harvey SB. Road to resilience: a systematic review and meta-analysis of resilience training programmes and interventions. BMJ Open. 2018 Jun;8(6):e017858.

12. Schutte NS, Malouff JM. The impact of signature character strengths interventions: A meta-analysis. J Happiness Stud. 2019 Apr;20(4):1179-96.

13. Peterson C, Park N, Seligman ME. Greater strengths of character and recovery from illness. J Posit Psychol. 2006 Jan;1(1):17-26.

14. Martínez-Martí ML, Ruch W. Character strengths predict resilience over and above positive affect, self-efficacy, optimism, social support, self-esteem, and life satisfaction. J Posit Psychol. 2017 Mar;12(2):110-9.

15. Li T, Duan W, Guo P. Character strengths, social anxiety, and physiological stress reactivity. PeerJ. 2017 May;5:e3396.

16. Kashdan TB, Julian T, Merritt K, Uswatte G. Social anxiety and posttraumatic stress in combat veterans: relations to well-being and character strengths. Behav Res Ther. 2006 Apr;44(4):561-83.

17. Meadows MP, Shreffler KM, Mullins-Sweatt SN. Occupational stressors and resilience in critical occupations: The role of personality. In The role of individual differences in occupational stress and well being 2011 Aug 10. Emerald Group Publishing Limited.
18. Smith BW, Dalen J, Wiggins K, Tooley E, Christopher P, Bernard J. The brief resilience scale: assessing the ability to bounce back. Int J Behav Med. 2008;15(3):194-200.

19. George D, Mallery M. Using SPSS for Windows step by step: a simple guide and reference.

20. Karreman A, Vingerhoets AJ. Attachment and well-being: the mediating role of emotion regulation and resilience. Pers Individ Dif. 2012 Nov;53(7):821-6.

21. Meredith LS, Sherbourne CD, Gaillot SJ, Hansell L, Ritschard HV, Parker AM, et al. Promoting Psychological Resilience in the U.S. Military. Rand Health Q. 2011 Jun;1(2):2.

22. Stephens JP, Heaphy ED, Carmeli A, Spreitzer GM, Dutton JE. Relationship quality and virtuousness: emotional carrying capacity as a source of individual and team resilience. J Appl Behav Sci. 2013 Mar;49(1):13-41.

23. Wagaman MA, Geiger JM, Shockley C, Segal EA. The role of empathy in burnout, compassion satisfaction, and secondary traumatic stress among social workers. Soc Work. 2015 Jul;60(3):201-9.

24. Gleichgerrcht E, Decety J. Empathy in clinical practice: how individual dispositions, gender, and experience moderate empathic concern, burnout, and emotional distress in physicians. PLoS One. 2013 Apr;8(4):e61526.

25. Turgoose D, Glover N, Barker C, Maddox L. Empathy, compassion fatigue, and burnout in police officers working with rape victims. Traumatology. 2017;23(2):205-13.

26. Wagnild G. A review of the Resilience Scale. J Nurs Meas. 2009;17(2):105-13. 